\title{
Radiotherapy of brain metastases from breast cancer: Treatment results and prognostic factors
}

\author{
JULIA KÜHNÖL ${ }^{1}$, CASPAR KÜHNÖL ${ }^{2}$ and DIRK VORDERMARK ${ }^{1}$ \\ Departments of ${ }^{1}$ Radiation Oncology and ${ }^{2}$ Paediatrics, Martin Luther University Halle-Wittenberg, \\ D-06120 Halle (Saale), Saxony-Anhalt, Germany
}

Received May 27, 2015; Accepted February 25, 2016

DOI: $10.3892 / 01.2016 .4349$

\begin{abstract}
Brain metastases (BM) from breast cancer are associated with high morbidity and a poor prognosis. The aim of this study was to analyse the role of radiotherapy in treatment of BM from breast cancer in the context of modern local therapy modalities, current systemic treatment options and prognostic factors. A retrospective analysis of 86 consecutive female patients treated with radiotherapy for BM from breast cancer between 2000 and 2010 was conducted. Patient and treatment characteristics were registered and survival data calculated. All patients received whole-brain radiotherapy (WBRT) with a median dose of $36 \mathrm{~Gy}$, and 19 patients were treated with an additional boost; this included fractionated schemes (median dose, 18 Gy) and radiosurgery (5 and 17 Gy). The median overall survival time from the start of WBRT was 4.1 months in the present cohort. Patients receiving a boost survived 19.7 months in comparison to 3.1 months for patients treated with WBRT alone $(\mathrm{P}<0.001)$. Other factors that improved overall survival, based on a univariate analysis, were dose of WBRT and number of BM. There was no statistical evidence for the influence of the human epidermal growth factor receptor 2 status on survival in the current study. The administration of boost treatment following WBRT was also identified as a significant factor influencing survival on multivariate analysis $(\mathrm{P}=0.030)$. In conclusion, radiotherapy affects the survival time of patients with BM from breast cancer. In particular, the implementation of boost treatment following WBRT in selected patients seems to extend survival time.
\end{abstract}

Correspondence to: Professor Dirk Vordermark, Department of Radiation Oncology, Martin Luther University Halle-Wittenberg, 40 Ernst-Grube-Straße, D-06120 Halle (Saale), Saxony-Anhalt, Germany

E-mail: dirk.vordermark@uk-halle.de

Abbreviations: BM, brain metastasis/metastases; ER, estrogen receptor; PR, progesterone receptor; HR, hormone receptor; HER2, human epidermal growth factor receptor 2; WBRT, whole-brain radiotherapy; SRS, stereotactic radiosurgery

Key words: radiotherapy, brain metastases, breast cancer

\section{Introduction}

The most common brain tumours are intracranial metastases (1). Over $20 \%$ of patients with solid malignant tumours develop brain metastases (BM); patients with small-cell lung cancer (45\%), melanomas (45\%), non-small-cell lung cancer (30\%), breast cancer and renal cancer $(20 \%)$ have the highest risk for the occurrence of intracranial metastases (2). The incidence of clinically detected BM in patients with metastatic breast cancer is $16-20 \%$, and autopsy studies suggest a prevalence of BM of up to 34\% (3-6). A number of risk factors for cerebral metastases in breast cancer patients have been reported in the literature; in addition to young age ( $<35$ years), large primary tumour size $(>2 \mathrm{~cm})$ and negative estrogen receptor (ER) status, the overexpression of human epidermal growth factor receptor 2 (HER2) has been demonstrated to be associated with a higher risk of BM (7-10).

The management of BM includes radiotherapeutic, surgical and medical options. Consideration of a local treatment modality depends on the number of intracranial metastases and potential local complications resulting from their location and size. Patients with multiple BM typically receive whole-brain radiotherapy (WBRT), whilst neurosurgery or stereotactic radiosurgery (SRS) are possible treatment options for patients with a single BM. The application of intrathecal chemotherapy may be selected as the therapeutic regime in cases with meningeal involvement (11).

The aim of the current study was to characterise the role of radiotherapy in patients with BM from metastatic breast cancer in the context of modern local therapy modalities, current systemic treatment options and prognostic factors.

\section{Patients and methods}

Patients. The current retrospective analysis was conducted on female patients with BM from breast cancer who were treated at the Department of Radiation Oncology of Martin Luther University Halle-Wittenberg [Halle (Saale), Germany] between the January 2000 and December 2010. A total of 86 consecutive patients were identified. Patient charts were reviewed to obtain data regarding the primary tumour, including the date of diagnosis, ER status and HER2 status, in addition to data on the diagnosis of metastatic disease, including BM, as well as treatment and follow-up information. Survival status was 
determined via local registry offices for each patient. This retrospective analysis was performed in concordance with the Helsinki declaration.

Statistical analysis. Overall survival was defined as the time from the start of radiotherapy of BM until the date of mortality or last follow-up. Patients were censored if alive at last follow-up. Survival analyses were performed using SPSS software version 19 (IBM SPSS, Armonk, NY, USA). Survival times were calculated by the Kaplan-Meier method, and survival of subgroups was compared by log-rank test. $\mathrm{P}<0.050$ was considered to indicate a statistically significant difference. In order to identify confounding factors, the multivariate Cox regression method was used.

\section{Results}

Baseline characteristics. Patient characteristics are presented in Table I. The age at initial diagnosis ranged from 26 to 81 years (median, 57.7 years) in the present cohort. In 38 cases (44.2\%), there was detection of ER or progesterone receptor (PR) or both; 39 patients (45.4\%) had hormone receptor (HR)-negative breast cancer at diagnosis. The HER2-overexpressing group, including those with HER2 expression detected at any time, contained 35 patients (40.7\%). BM were diagnosed via computed tomography (29\%) or magnetic resonance imaging (64\%), whilst the type of imaging was not documented in $7 \%$. The median time from diagnosis of primary tumour until detection of BM was 33.4 months (range, 0-391.03 months). More than $3 \mathrm{BM}$ were found in 55 patients $(64.0 \%)$. There were 34 patients $(39.5 \%)$ in whom the diameter of the largest $\mathrm{BM}$ was $\leq 20 \mathrm{~mm}$.

Therapy for BM included WBRT for all patients. The dose ranged from 3 to 46 Gy (median dose, 36 Gy; early termination after $3 \mathrm{~Gy}$ in two cases). In addition a boost treatment was applied in 19 patients (22.1\%): 1 patient received a single-fraction boost, 15 patients were treated with a fractionated scheme and 3 patients received both types of boost. The median total dose of fractionated boost treatment was 18 Gy (range, 6-30 Gy). The doses for single-fraction boost were 5 Gy ( 1 case) and 17 Gy ( 3 cases). In 53\% of patients, systemic therapy (chemotherapy, hormonotherapy or therapy with the monoclonal antibody against HER2, trastuzumab) was applied following the commencement of brain irradiation. Taxanes and capecitabine were the most frequently used chemotherapeutic agents, and 17 patients (19.8\%) were treated with trastuzumab.

Survival. The median survival time from the beginning of radiotherapy of BM in the entire cohort was 4.14 months (Fig. 1). The median age at the beginning of radiotherapy was 58.0 years. Patients younger than 58 years survived a median of 4.0 months, whilst patients older than this survived 4.14 months $(\mathrm{P}=0.592)$.

There was no statistical evidence for the effect of initial tumour stage or grade on survival. The median survival times according to stage and grade were as follows: T1, 3.8 months; T2, 3.1 months; T3, 2.5 months; T4, 4.7 months (T-stage, $\mathrm{P}=0.642) ; \mathrm{N} 1,3.7$ months; N2, 2.9 months; N3, 4.3 months (N-stage, $\mathrm{P}=0.468) ; \mathrm{M} 0,3.8$ months; M1 7.7 months (M-stage,

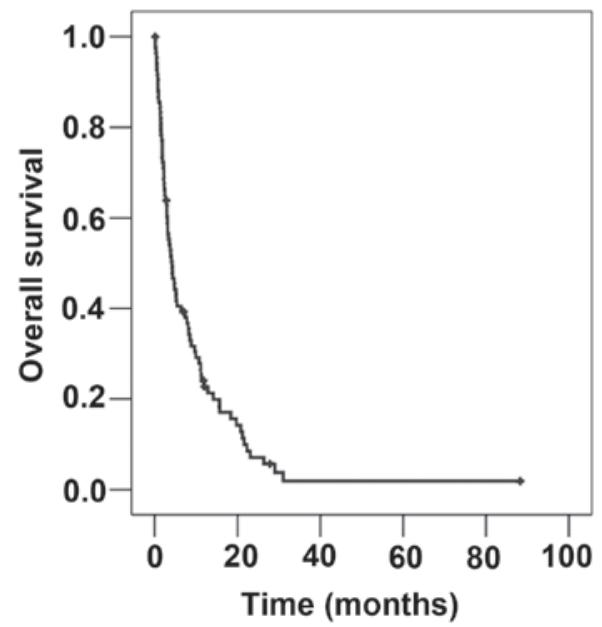

Figure 1. Overall survival of the entire cohort $(n=86)$ from the commencement of radiotherapy of brain metastases.

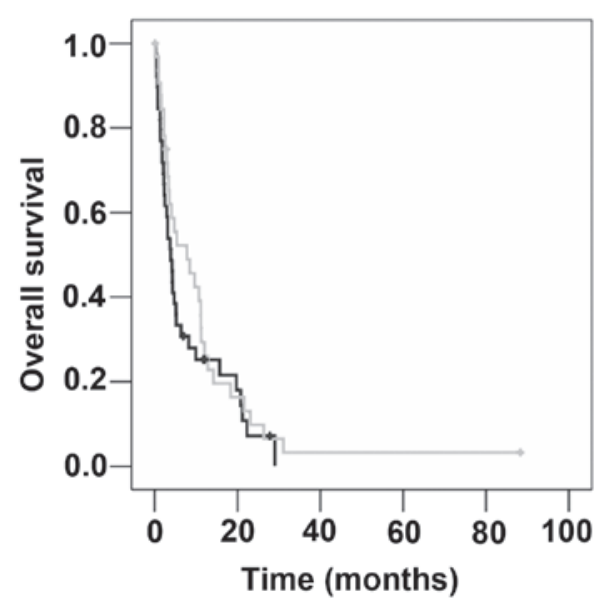

Figure 2. Overall survival following brain irradiation, according to HER2 status (light grey, HER2 positive; dark grey, HER2 negative; $\mathrm{P}=0.317$ ). HER2, human epidermal growth factor receptor 2.

$\mathrm{P}=0.265$ ); G1/G2, 6.3 months; G3, 3.5 months (grade, $\mathrm{P}=0.250$ ). Similarly, HR-status did not influence survival in this study. Patients with HR-positive breast cancer survived 4.2 months vs. 4.1 months for women with HR-negative disease $(\mathrm{P}=0.683)$. The median survival time in the group with HER2-overexpressing metastatic breast cancer was longer than that of patients with HER2 non-overexpressing disease (7.7 vs. 3.8 months), but this difference was not significant $(\mathrm{P}=0.317$; Fig. 2). Localisation of distant metastases, histology of primary tumour, diameter of largest BM and treatment with trastuzumab were also factors that did not significantly influence survival.

On univariate analysis, the median survival time of patients who underwent surgery was significantly longer than those who did not undergo surgery with (26.4 months vs. 4.0 months; $\mathrm{P}=0.003)$. The investigation of WBRT-dose revealed a median survival time of 2.2 months for patients treated with $\leq 35 \mathrm{~Gy}$ vs. 8.5 months for those treated with $>35$ Gy $(\mathrm{P}=0.001)$. Another significant factor was the use of boost irradiation subsequent to WBRT (boost vs. no boost, 19.7 vs. 3.1 months; $\mathrm{P}<0.001$; Fig. 3; Table II). 
Table I. Patient characteristics $(n=86)$.

\begin{tabular}{l} 
Parameter \\
\hline Age at diagnosis of BM, years \\
Median \\
Range \\
T stage of primary tumour \\
T1 \\
T2 \\
T3 \\
T4 \\
Tx/n.a.
\end{tabular}

$\mathrm{N}$ stage of primary tumour

N0
N1
N2
N3
Nx/n.a.
M stage of primary tumour
M0
M1
Mx/n.a.

Grade of primary tumour

G1
G2
G3
Gx/n.a.

HR status of primary tumour

$$
\begin{aligned}
& \text { ER-positive } \\
& \text { PR-positive } \\
& \text { ER+PR-positive } \\
& \text { HR-negative } \\
& \text { n.a. }
\end{aligned}
$$

HER2-status ${ }^{\text {a }}$

\section{Positive}

Negative

n.a.

$$
\begin{gathered}
28(32.5 \%) \\
40(46.5 \%) \\
4(4.7 \%) \\
5(5.8 \%) \\
9(10.5 \%)
\end{gathered}
$$

$50(58.1 \%)$

$21(24.4 \%)$

$15(17.5 \%)$

$2(2.3 \%)$

$33(38.4 \%)$

$40(46.5 \%)$

$11(12.8 \%)$

$9(10.5 \%)$

$2(2.3 \%)$

$27(31.4 \%)$

$39(45.4 \%)$

$9(10.4 \%)$

$35(40.7 \%)$

$39(45.3 \%)$

$12(14.0 \%)$

Extracranial disease

Bone only/no visceral metastases

Bone+visceral or only visceral metastases n.a.

$13(15.1 \%)$

$70(81.4 \%)$

$3(3.5 \%)$

BM: number of lesions

$$
\begin{aligned}
& \leq 3 \\
& >3
\end{aligned}
$$$$
\text { n.a. }
$$

$20(23.3 \%)$

$55(63.9 \%)$

$11(12.8 \%)$

BM: diameter of largest lesion

$$
\begin{aligned}
& \leq 20 \mathrm{~mm} \\
& >20 \mathrm{~mm} \\
& \text { n.a. }
\end{aligned}
$$

BM: type of therapy

$$
\begin{aligned}
& \text { Surgery } \\
& \text { WBRT }
\end{aligned}
$$

Boost
$34(39.5 \%)$

$22(25.6 \%)$

$30(34.9 \%)$

$6(6.9 \%)$

$86(100 \%)$

$19(22.1 \%)$

Table I. Continued.

\begin{tabular}{lc}
\hline Parameter & Value \\
\hline WBRT, total dose & \\
$30 \mathrm{~Gy}$ & $25(29.1 \%)$ \\
$36 \mathrm{~Gy}$ & $40(46.5 \%)$ \\
$40 \mathrm{~Gy}$ & $5(5.8 \%)$ \\
Other & $16(18.6 \%)$ \\
Boost treatment & \\
Single & $1(1.2 \%)$ \\
Fractionated & $15(17.4 \%)$ \\
Single+fractionated & $3(3.5 \%)$ \\
No boost & $67(77.9 \%)$ \\
\end{tabular}

${ }^{a}$ Any HER2-status (primary tumour, metastasis or relapse). BM, brain metastases; n.a, not available; ER, estrogen receptor; PR, progesterone receptor; HR, hormone receptor; HER2, human epidermal growth factor receptor 2; WBRT, whole-brain radiotherapy

Table II. Results of univariate and multivariate analyses.

\begin{tabular}{lcc}
\hline & \multicolumn{2}{c}{ P-value } \\
\cline { 2 - 3 } Variable & $\begin{array}{c}\text { Log-rank } \\
\text { test }\end{array}$ & $\begin{array}{c}\text { Cox } \\
\text { regression }\end{array}$ \\
\hline Number of brain metastases & 0.050 & 0.200 \\
Surgery & 0.003 & 0.164 \\
Whole-brain radiotherapy dose & 0.001 & 0.063 \\
Boost treatment & $<0.001$ & 0.030 \\
Chemotherapy & 0.050 & 0.433
\end{tabular}

The number of BM was slightly associated with survival time: Patients with $\leq 3 \mathrm{BM}$ survived 7.3 months compared with 4.0 months in patients with $>3 \mathrm{BM}(\mathrm{P}=0.050)$. Equally, marginally prolonged survival was observed in patients receiving chemotherapy following the commencement of radiation therapy compared with those who did not receive chemotherapy (2.1 vs. 1.3 months; $\mathrm{P}=0.050)$.

All factors that appeared to exhibit a slight trend $(\mathrm{P}<0.100)$ on univariate analysis were included in a multivariate Cox regression analysis (Table II). According to this analysis, only boost treatment following WBRT was a statistically significant factor affecting survival time $(\mathrm{P}=0.030)$.

\section{Discussion}

In the present study of patient with BM from breast cancer, the median overall survival time for the entire group of patients was 4.14 months. In comparison to other data in the literature, this interval is slightly shorter; median survival times between 4.5 and 10 months have been reported (12-16).

A number of studies have reported a significantly longer survival time for patients with BM in HER2-overexpressing breast cancer (17-19). In the present analysis, a non-significantly 
prolonged median survival time of patients with HER2-positive disease was observed. These findings may be explained by the so-called HER2-paradigm (20). Thereby, specific therapy against HER2 with trastuzumab, typically combined with other chemotherapeutic agents, leads to improved extracranial tumour control compared to HER-2-negative patients, potentially increasing the risk of intracranial metastasis, since the brain may become a sanctuary site for tumor cells (21). Le Scodan et al (15) determined survival times in the groups HER2 non-overexpressing patients, HER2-overexpressing patients without trastuzumab treatment and HER2-overexpressing patients with trastuzumab treatment of 5.9, 5.6 and 19.53 months, respectively $(\mathrm{P}<0.004)$. The corresponding survival times in a study by Church et al (22) were 3.8, 3.0 and 11.9 months. In the present cohort, a similar trend was observed (3.8 vs. 3.5 vs. 9.7 months, respectively).

Besides medical treatment of metastatic breast cancer, surgical and radiotherapeutic options are available. In the present cohort, surgical resection was typically performed in patients with a solitary brain metastasis. It is well established that a smaller number of BM is associated with longer survival $(7,14,15,23)$. In the present cohort, the group of patients that underwent surgical resection was very small. Several reports in the literature focused on the comparison of local therapy (surgery/radiosurgery) of BM in combination with WBRT vs. WBRT alone; a survival benefit was observed for selected patients treated with combinations of local therapy and WBRT $(24,25)$. In addition, the application of local therapy alone may be justified. A randomised trial reported by Kocher et al (16) compared patients with $\leq 3 \mathrm{BM}$ of distinct solid tumours who were treated with surgery/radiosurgery with or without WBRT. The published data indicated that there is a reduction of intracranial relapse and neurological deaths in patients with a limited number of BM if treatment with local therapy plus WBRT is administered. SRS and surgery also seemed to produce similar results (26).

WBRT alone is used in cases with multiple BM or in patients with a limited number of BM when surgery or SRS is not possible (2). A dose of 30-36 Gy is commonly applied. The present analysis revealed a survival advantage for patients treated with a higher dose of WBRT (>35 Gy). This topic is controversial in the literature. Certain authors evaluated various radiation schemes and were unable to detect improved survival if patients were treated with a total dose $>30$ Gy (27-29). By contrast, two retrospective studies by Mahmoud-Ahmed et al (30) and Meyer et al (31) observed a survival benefit in patients who were treated with a WBRT dose of $>30 \mathrm{~Gy}$. It is unclear whether these findings are associated with a selection bias. If a dose of $>30$ Gy is used, it may be given preferentially to patients with a better prognosis due to younger age, limited number of BM and higher Karnofsky performance status (2). On the other hand, higher WBRT doses may be used for patients who are not candidates for a boost due to higher number of metastases.

Multivariate analysis conducted in the current study identified only boost irradiation following WBRT as having an significant effect on survival. In comparison to other trials, the median survival time of 19.7 months for this subgroup is relatively long. For example, Hsu et al (32) reported a median survival time in patients with metastatic cancer from different

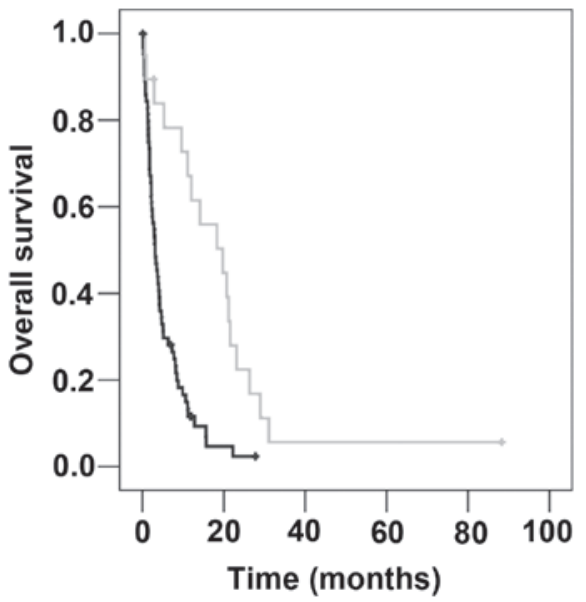

Figure 3. Overall survival following brain irradiation, according to boost treatment (light grey, boost; dark grey, no boost; $\mathrm{P}<0.001$ ).

tumour entities of 12.1 months if they were treated with stereotactic boost irradiation following WBRT. Another analysis by Kondziolka et al (33) revealed a survival time of 11 months following a combination of WBRT and SRS treatment. In a study by Andrews et al (34), survival subsequent to WBRT plus boost irradiation was 6.5 months in patients with a single BM. Furthermore, Assouline et al (35) reported that patients with $\leq 3 \mathrm{BM}$ from lung cancer, breast cancer or melanoma survived significantly longer if treated with WBRT plus boost treatment compared with WBRT alone (8.9 vs. 4.0 months; $\mathrm{P}=0.002$ ). Despite the significant association of boost treatment with improved survival in the present study, the findings must be interpreted with caution. Patients who received boost treatment subsequent to WBRT were those with a limited number of BM. Considering the studies discussed, survival is improved in breast cancer patients with a limited number of BM who are treated with boost following WBRT.

Recently, the application of WBRT in patients with single $\mathrm{BM}$ has been discussed controversially in the literature. In summary, local control is improved, but there is no effect on overall survival time if patients are treated with WBRT following surgery or SRS $(16,36)$. In addition, SRS plus WBRT affects learning and memory function more than SRS alone (37). Patients with multiple cerebral metastases are seldom treated with boost irradiation. Whether a local enhancement of dose is considered reasonable depends on the number, localisation and size of the BM. To date, no randomised clinical trials have examined the effects of SRS on survival in patients with multiple BM. However, a prospective observational study by Yamamoto et al (38) revealed no inferiority for the management of $\leq 10 \mathrm{BM}$ with SRS; the median overall survival time was similar in the groups with 2-4 BM vs. 5-10 BM (10.8 months for both), as was the documented toxicity.

In conclusion, within the constraints of a retrospective analysis, the results of the present study inform about the current efficacy of brain irradiation in patients with BM from metastatic breast cancer. In particular boost irradiation following WBRT improved survival times in selected patients. Although there was no statistical evidence for the effect of HER2 in this data set, it appears to be a relevant variable affecting survival in larger cohorts. 


\section{References}

1. Gavrilovic IT and Posner JB: Brain metastases: Epidemiology and pathophysiology. J Neurooncol 75: 5-14, 2005.

2. German Society for Neurology: Brain metastases and meningeosis neoplastica. Leitlinien für Diagnostik und Therapie in der Neurologie: Registry Number 030/060, 2011 (In German).

3. DiStefano A, Yong Yap Y, Hortobagyi GN and Blumenschein GR: The natural history of breast cancer patients with brain metastases. Cancer 44: 1913-1918, 1979.

4. Cho SY and Choi HY: Causes of death and metastatic patterns in patients with mammary cancer. Ten-year autopsy study. Am J Clin Pathol 73: 232-234, 1980.

5. Lee YT: Breast carcinoma: Pattern of metastasis at autopsy. J Surg Oncol 23: 175-180, 1983.

6. Tsukada Y, Fouad A, Pickren JW and Lane WW: Central nervous system metastasis from breast carcinoma. Autopsy study. Cancer 52: 2349-2354, 1983.

7. Evans AJ, James JJ, Cornford EJ, Chan SY, Burrell HC, Pinder SE, Gutteridge E, Robertson JF, Hornbuckle J and Cheung KL: Brain metastases from breast cancer: Identification of a high-risk group. Clin Oncol (R Coll Radiol) 16: 345-349, 2004.

8. Zeichner SB, Cavalcante L, Suciu GP, Ruiz AL, Hirzel A and Krill-Jackson E: Long-term survival of women with locally advanced breast cancer with $\geq 10$ involved lymph nodes at diagnosis. Asian Pac J Cancer Prev 15: 3435-3441, 2014.

9. Pestalozzi BC, Zahrieh D, Price KN, Holmberg SB, Lindtner J, Collins J, Crivellari D, Fey MF, Murray E, Pagani O, et al: Identifying breast cancer patients at risk for central nervous system (CNS) metastases in trials of the international breast cancer study group (IBCSG). Ann Oncol 17: 935-944, 2006.

10. Gabos Z, Sinha R, Hanson J, Chauhan N, Hugh J, Mackey JR and Abdulkarim B: Prognostic significance of human epidermal growth factor receptor positivity for the development of brain metastasis after newly diagnosed breast cancer. J Clin Oncol 24 5658-5663, 2006.

11. Kreienberg R, Albert US, Follmann M, Kopp IB, Kühn T and Wöckel A: Interdisciplinary GoR level III Guidelines for the Diagnosis, Therapy and Follow up Care of Breast Cancer: Short version AWMF Registry No.: 032 045OL AWMF Register Nummer: 032 045OL Kurzversion 3.0, Juli 2012. Geburtshilfe Frauenheilkd 73: 556-583, 2013

12. Karam I, Nichol A, Woods R and Tyldesley S: Population-based outcomes after whole brain radiotherapy and re-irradiation in patients with metastatic breast cancer in the trastuzumab era. Radiat Oncol 6: 181, 2011.

13. Ogawa K, Yoshii Y, Nishimaki T, Tamaki N, Miyaguni $T$, Tsuchida Y, Kamada Y, Toita T, Kakinohana Y, Tamaki W, et al: Treatment and prognosis of brain metastases from breast cancer. J Neurooncol 86: 231-238, 2008.

14. Dawood S, Gonzalez-Angulo AM, Albarracin C, Yu TK, Hortobagyi GN, Buchholz TA and Woodward WA: Prognostic factors of survival in the trastuzumab era among women with breast cancer and brain metastases who receive whole brain radiotherapy: A single-institution review. Cancer 116: 3084-3092, 2010.

15. Le Scodan R, Jouanneau L, Massard C, Gutierrez M, Kirova Y, Cherel P, Gachet J, Labib A and Mouret-Fourme E: Brain metastases from breast cancer: Prognostic significance of HER-2 overexpression, effect of trastuzumab and cause of death. BMC Cancer 11: 395, 2011.

16. Kocher M, Soffietti R, Abacioglu U, Villà S, Fauchon F, Baumert BG, Fariselli L, Tzuk-Shina T, Kortmann RD, Carrie C, et al: Adjuvant whole-brain radiotherapy versus observation after radiosurgery or surgical resection of one to three cerebral metastases: Results of the EORTC 22952-26001 study. J Clin Oncol 29: 134-141, 2011

17. Nam BH, Kim SY, Han HS, Kwon Y, Lee KS, Kim TH and Ro J: Breast cancer subtypes and survival in patients with brain metastases. Breast Cancer Res 10: R20, 2008.

18. Anders CK, Deal AM, Miller CR, Khorram C, Meng H, Burrows E, Livasy C, Fritchie K, Ewend MG, Perou CM and Carey LA: The prognostic contribution of clinical breast cancer subtype, age, and race among patients with breast cancer brain metastases. Cancer 117: 1602-1611, 2011.

19. Sperduto PW, Kased N, Roberge D, Chao ST, Shanley R, Luo X, Sneed PK, Suh J, Weil RJ, Jensen AW, et al: The effect of tumor subtype on the time from primary diagnosis to development of brain metastases and survival in patients with breast cancer. J Neurooncol 112: 467-472, 2013.
20. Lin NU and Winer EP: Brain metastases: The HER2 paradigm. Clin Cancer Res 13: 1648-1655, 2007.

21. Gabos Z, Sinha R, Hanson J, Chauhan N, Hugh J, Mackey JR and Abdulkarim B: Prognostic significance of human epidermal growth factor receptor positivity for the development of brain metastasis after newly diagnosed breast cancer. J Clin Oncol 24 : 5658-5663, 2006.

22. Church DN, Modgil R, Guglani S, Bahl A, Hopkins K, Braybrooke JP, Blair P and Price CG: Extended survival in women with brain metastases from HER2 overexpressing breast cancer. Am J Clin Oncol 31: 250-254, 2008.

23. Liu MT, Hsieh CY, Wang AY, Chang TH, Pi CP, Huang CC, Huang $\mathrm{CY}$ and Liou $\mathrm{CH}$ : Prognostic factors affecting the outcome of brain metastases from breast cancer. Support Care Cancer 14: 936-942, 2006.

24. Patchell RA, Tibbs PA, Walsh JW, Dempsey RJ, Maruyama Y, Kryscio RJ, Markesbery WR, Macdonald JS and Young B: A randomized trial of surgery in the treatment of single metastases to the brain. N Engl J Med 322: 494-500, 1990.

25. Rades D, Kieckebusch S, Haatanen T, Lohynska R, Dunst J and Schild SE: Surgical resection followed by whole brain radiotherapy versus whole brain radiotherapy alone for single brain metastasis. Int J Radiat Oncol Biol Phys 70: 1319-1324, 2008.

26. O'Neill BP, Iturria NJ, Link MJ, Pollock BE, Ballman KV and O'Fallon JR: A comparison of surgical resection and stereotactic radiosurgery in the treatment of solitary brain metastases. Int J Radiat Oncol Biol Phys 55: 1169-1176, 2003.

27. Murray KJ, Scott C, Greenberg HM, Emami B, Seider M, Vora NL, Olson C, Whitton A, Movsas B and Curran W: A randomized phase III study of accelerated hyperfractionation versus standard in patients with unresected brain metastases: A report of the radiation therapy oncology group (RTOG) 9104. Int J Radiat Oncol Biol Phys 39: 571-574, 1997.

28. Rades D, Haatanen T, Schild SE and Dunst J: Dose escalation beyond 30 grays in 10 fractions for patients with multiple brain metastases. Cancer 110: 1345-1350, 2007.

29. Davey P, Hoegler D, Ennis M and Smith J: A phase III study of accelerated versus conventional hypofractionated whole brain irradiation in patients of good performance status with brain metastases not suitable for surgical excision. Radiother Oncol 88: 173-176, 2008.

30. Mahmoud-Ahmed AS, Suh JH, Lee SY, Crownover RL and Barnett GH: Results of whole brain radiotherapy in patients with brain metastases from breast cancer: A retrospective study. Int J Radiat Oncol Biol Phys 54: 810-817, 2002.

31. Meyer A, Steinmann D, Malaimare L, Karstens JH and Bremer M: Prediction of prognosis regarding fractionation schedule and survival in patients with whole-brain radiotherapy for metastatic disease. Anticancer Res 28: 3965-3969, 2008.

32. Hsu F, Kouhestani P, Nguyen S, Cheung A, McKenzie M, Ma R, Toyota B and Nichol A: Population-based outcomes of boost versus salvage radiosurgery for brain metastases after whole brain radiotherapy. Radiother Oncol 108: 128-131, 2013.

33. Kondziolka D, Patel A, Lunsford LD, Kassam A and Flickinger JC: Stereotactic radiosurgery plus whole brain radiotherapy versus radiotherapy alone for patients with multiple brain metastases. Int J Radiat Oncol Biol Phys 45: 427-434, 1999.

34. Andrews DW, Scott CB, Sperduto PW, Flanders AE, Gaspar LE, Schell MC, Werner-Wasik M, Demas W, Ryu J, Bahary JP, et al: Whole brain radiation therapy with or without stereotactic radiosurgery boost for patients with one to three brain metastases: Phase III results of the RTOG 9508 randomised trial. Lancet 363: 1665-1672, 2004.

35. Assouline A, Levy A, Chargari C, Lamproglou I, Mazeron JJ and Krzisch C: Whole brain radiotherapy: Prognostic factors and results of a radiation boost delivered through a conventional linear accelerator. Radiother Oncol 99: 214-217, 2011.

36. Aoyama H, Shirato H, Tago M, Nakagawa K, Toyoda T, Hatano K, Kenjyo M, Oya N, Hirota S, Shioura H, et al: Stereotactic radiosurgery plus whole-brain radiation therapy vs stereotactic radiosurgery alone for treatment of brain metastases: A randomized controlled trial. JAMA 295: 2483-2491, 2006.

37. Chang EL, Wefel JS, Hess KR, Allen PK, Lang FF, Kornguth DG, Arbuckle RB, Swint JM, Shiu AS, Maor MH and Meyers CA: Neurocognition in patients with brain metastases treated with radiosurgery or radiosurgery plus whole-brain irradiation: A randomised controlled trial. Lancet Oncol 10: 1037-1044, 2009.

38. Yamamoto M, Serizawa T, Shuto T, Akabane A, Higuchi Y, Kawagishi J, Yamanaka K, Sato Y, Jokura H, Yomo S, et al: Stereotactic radiosurgery for patients with multiple brain metastases (JLGK0901): A multi-institutional prospective observational study. Lancet Oncol 15: 387-395, 2014. 